\title{
Unemployment, Imperfect Risk Sharing, and the Monetary Business Cycle
}

\author{
Gregory E. Givens* \\ Assistant Professor of Economics \\ Department of Economics and Finance \\ Jennings A. Jones College of Business \\ Middle Tennessee State University \\ Murfreesboro, TN 37132 \\ ggivens@mtsu . edu
}

First Draft: May 2007

\begin{abstract}
This paper examines the impact of unemployment insurance on the propagation of monetary disturbances in a staggered price model of the business cycle. To motivate a role for risk sharing behavior, I construct a quantitative equilibrium model that gives prominence to an efficiency-wage theory of unemployment based on imperfectly observable labor effort. Dynamic simulations reveal that under a full insurance arrangement, staggered price-setting is incapable of generating persistent real effects of a monetary shock. Introducing partial insurance, however, bolsters the amount of endogenous wage rigidity present in the model, enriching the propagation mechanism. Positive real persistence appears in versions of the model that exclude capital accumulation as well as in versions that do not.
\end{abstract}

Keywords: Unemployment, Partial Insurance, Staggered Prices, Endogenous Persistence JEL Classification: E24, E31, E32, E52

\footnotetext{
${ }^{*}$ I have benefited greatly from helpful discussions with Stuart Fowler, Johanna Francis, Richard Froyen, Mark Owens, Michael Salemi, and participants at the 2007 Western Economic Association International Annual Conference. I assume full responsibility for all remaining errors and omissions.
} 


\section{Introduction}

Numerous empirical studies reflect a consensus among macroeconomists that monetary policy shocks have persistent effects on aggregate measures of real activity (e.g., Leeper, Sims, and Zha (1996) and Christiano, Eichenbaum, and Evans (1999)). To explain such persistence within the context of a quantitative model of the economy, many believe that price-staggering along the lines of Taylor (1980) and Blanchard (1983) is essential. Models that graft this kind of friction into a general equilibrium framework, however, have had difficulty capturing the persistence evident in the data. ${ }^{1}$

In a seminal contribution, Chari, Kehoe, and McGratten (2000) (henceforth, CKM) argue that equilibrium models with small nominal frictions alone possess weak internal propagation mechanisms. Specifically, the duration of output persistence following a monetary shock does not exceed the imposed length of price fixity in the model. An unappealing consequence of this finding is that significant persistence can only be obtained if one is willing to assume a high degree of exogenous rigidity. They go on to show that the inability to return longer episodes of endogenous persistence is a result of the procyclical nature of real marginal cost. With price staggering as the sole friction, changes in aggregate demand translate into considerable variation in marginal cost, particularly real wages. As a result, firms respond by making large price adjustments when they have an opportunity to do so, inducing smaller, less persistent movements in output.

This discovery led to the development of an extensive literature aimed at identifying various auxiliary frictions that enhance the propagation mechanism by dampening the sensitivity of marginal cost. In a model characterized by monopolistically competitive labor markets, Andersen (1998) and Huang and Liu (2002) demonstrate that staggered nominal wage-setting as an alternative to staggered price-setting enables the New Keynesian model

\footnotetext{
${ }^{1}$ Goodfriend and King (1997) brand models that fit this category the "New Neoclassical Synthesis." Some early examples include Cho and Cooley (1995), King and Watson (1996), Rotemberg (1996), and Yun (1996).
} 
to deliver persistent real effects of a monetary shock. Basu (1995) and Bergin and Feenstra (2000) incorporate a roundabout production structure in which all goods are material inputs for the production of other goods, implying that firm-level marginal cost depends on the prices charged by all other firms. Huang and Liu (2001) consider a vertical input-output structure in which finished goods go through multiple stages of production and firms encounter sticky prices at each phase of assembly. Neiss and Pappa (2005) and Dotsey and King (2006) emphasize the role of variable factor utilization in strengthening the propagation of nominal disturbances. Kiley (1997a) demonstrates that increasing returns to labor diminishes the elasticity of marginal cost with respect to output.

In this paper I add to the body of work referenced above by examining a different source of real persistence, namely, imperfect risk sharing between employed and unemployed workers. ${ }^{2}$ To provide a rationale for risk sharing behavior, I build on the model recently developed by Alexopoulos (2004) in which firms are unable to perfectly monitor labor effort, implying that workers face a temptation to shirk after negotiating employment contracts. To elicit the desired effort level, firms lift wages to the point where one's utility from exerting effort is at least as great as the expected utility from shirking. Stated differently, equilibrium wage contracts must satisfy the workers' incentive compatibility constraint. The outcome of this arrangement involves the payment of an efficiency wage that exceeds the Walrasian market-clearing level, making unemployment a pervasive feature of the economy. Around this structural model of the labor market I add monopolistic competition with staggered price-setting in the spirit of Taylor (1980), money growth shocks as the exclusive source of exogenous fluctuation, and an unemployment insurance program that allows for varying degrees of risk sharing between agents in the model.

The scope of unemployment insurance affects persistence through its impact on the wage-

\footnotetext{
${ }^{2}$ Imperfect unemployment insurance has recently been studied by Nakajima (2005) regarding the consequences for optimal monetary policy and, similarly, by Nakajima (2006) as a source of real indeterminacy.
} 
setting process. Because effort is not perfectly observable, the feasible set of wages are restricted to those that satisfy the incentive compatibility constraint. It turns out that limiting the insurance opportunities available to workers reduces the sensitivity of real wages to changes in economic conditions that shift the incentive compatibility constraint. In particular, the wage increments needed to secure positive effort after a monetary expansion diminish as risk sharing activity declines. This is simply another way of stating that incomplete insurance interacts with unobservable effort to elevate the degree of endogenous wage rigidity present in the model. That is to say, firms choose to make smaller wage adjustments even though they are free to adjust every period. The presence of greater wage rigidity softens the response of marginal cost to demand shocks, encouraging firms to trim price adjustments when given the chance. More inertia in the price level, in turn, amplifies the persistence of real activity.

To assess the quantitative impact of partial insurance, I conduct dynamic simulations of the shirking model using structural parameters that are calibrated to match certain aspects of the U.S. data. In a version that abstracts from capital accumulation, I find that imperfect risk sharing generates output fluctuations that persist beyond the imposed duration of price rigidity. For the level of risk sharing permitted under the benchmark calibration, about 5 percent of the impact-period effect on output survives after all existing price contracts expire. When income pooling is scarce, however, persistence can be much higher with over 40 percent of the output effect remaining after the initial contract period ends. Under a full insurance arrangement, the model fails to deliver persistent real effects of a monetary shock, echoing the principle conclusion of CKM (2000). Simulation results also demonstrate that the persistence mechanism is not greatly impaired by the presence of capital, whereas previous studies have not always found this to be the case.

An interesting side effect of imperfect risk sharing is that it tends to create a tradeoff between two aspects of the business cycle: persistence and amplitude. Quantitative results 
indicate that as the amount of insurance coverage declines, the response profile of output becomes more persistent but the overall size of steady-state departures becomes smaller. Related studies find that amplitude either increases with or is mostly invariant to additional sources of persistence.

The paper is organized as follows. Section 2 develops the benchmark model and describes the calibration. Section 3 derives analytical solutions to a stripped-down version of the shirking model and then goes on to discuss simulation results from the full model. Section 4 examines the robustness of key findings to the presence of capital. Section 5 concludes.

\section{The Benchmark Model}

The benchmark economy blends a shirking, efficiency-wage theory of the labor market with monopolistic competition and staggered price-setting in the goods market. It is inhabited by five types of agents: a representative family, a continuum of family members, a competitive final good producer, a continuum of monopolistic intermediate good firms, and a monetary authority. In what follows, I describe the economic circumstances facing each agent.

\subsection{Households}

The household sector is characterized by a representative family with a continuum of members of measure one. Every period a fraction $N_{t}$ of members receive job offers, while the remaining $1-N_{t}$ are unemployed. Differences in employment status introduces heterogeneity into the model. To conserve the representative agent construct, I follow Alexopoulos (2004) in assuming that individuals are not permitted to transfer assets intertemporally. Instead, the family entity owns all assets and makes saving decisions on behalf of its members.

Assets include nominal bonds $B_{t}$ with state-contingent payoffs, money holdings $M_{t-1}$,

lump-sum transfers from the government $T_{t}$, and a flow of profits $\int_{0}^{1} \operatorname{Div} v_{t}(i) d i$ from ownership 
of a $[0,1]$ continuum of firms. Asset returns finance a complete portfolio of bonds $B_{t+1}$, future money holdings $M_{t}$, and a stream of consumption benefits $C_{t}^{f}$ that are distributed equally to all members. Thus, $C_{t}^{f}$ can be interpreted as a minimum level of guaranteed consumption. The household's period-by-period budget constraint is then given by

$$
P_{t} C_{t}^{f}+E_{t}\left[Q_{t, t+1} B_{t+1}\right]+M_{t}=B_{t}+M_{t-1}+\int_{0}^{1} \operatorname{Div}_{t}(i) d i+T_{t}
$$

where $P_{t}$ is the price of the consumption good and $Q_{t, t+1}$ is the stochastic discount factor.

In addition to its saving decisions, the family coordinates a fully funded insurance program aimed at reducing the income risk associated with unemployment. Working members contribute a portion of their earnings into a fund that is divided equally among nonworking members. I assume that individual contributions are governed by an exogenously specified formula that encompasses a wide range of different risk sharing possibilities. The scope of the insurance arrangement will ultimately determine the the ability of the model to generate persistent real effects of a monetary shock.

\subsubsection{Family Members}

Even though saving is prohibited, individuals can elevate their consumption above $C_{t}^{f}$ by working. Intermediate good firms negotiate one-period employment contracts that specify a real wage $w_{t}$, a fixed length of hours $h$, and a required level of effort $e_{t} \cdot{ }^{3}$ Because firms are unable to monitor effort perfectly, workers face a temptation to shirk. A shirker is defined as anyone whose effort level deviates from the contractually specified amount. Following Alexopoulos (2004), I assume that firms pay a fraction $s$ of the worker's wage bill at the beginning of the period, delivering the final portion at the end of the period as long as

\footnotetext{
${ }^{3}$ The notation does not indicate which firm the family member works for. It turns out that because producers share a common technology, employment contracts will be identical. Thus, I choose to drop firm-specific arguments in the current discussion.
} 
shirking goes undetected. A shirker is detected with exogenous probability $d$.

Under these conditions consumption may differ across members depending on whether or not one is employed and whether or not an employed worker is disciplined for shirking. The period- $t$ consumption of an employed worker who is not detected shirking is given by

$$
C_{t}^{e}=C_{t}^{f}+h w_{t}-f_{t}
$$

where $f_{t}$ denotes the unemployment-insurance fee. If caught shirking, workers surrender a payment in the amount of $(1-s) h w_{t}$. After contributing to the unemployment fund, the period- $t$ consumption of a detected shirker becomes

$$
C_{t}^{s}=C_{t}^{f}+s h w_{t}-f_{t}
$$

Insurance fees are distributed equally among unemployed members. With transfers $C_{t}^{f}$ from the family, the period- $t$ consumption of an unemployed individual is given by

$$
C_{t}^{u}=C_{t}^{f}+\frac{N_{t}}{1-N_{t}} f_{t}
$$

Individual insurance fees are determined by the formula

$$
f_{t}=\sigma\left(1-N_{t}\right) h w_{t}
$$

where $\sigma \in[0,1]$ governs the risk-sharing arrangement among family members. By setting $\sigma=1$, members become fully insured since $C_{t}^{e}=C_{t}^{u}$ in equilibrium. Fixing $\sigma=0$ eliminates wage pooling completely, rendering $C_{t}^{u}=C_{t}^{f}$ in equilibrium. Partial insurance follows from setting $0<\sigma<1$, in which case $C_{t}^{f}<C_{t}^{u}<C_{t}^{e}$. In simulation exercises, I assess the model's dynamic properties for numerous values of $\sigma$ ranging from full insurance to no insurance. 
The momentary utility function of an individual who consumes $C_{t}$ and whose family owns money holdings in the amount $M_{t}$ is given by

$$
U\left(C_{t}, e_{t}, \frac{M_{t}}{P_{t}}\right)=\ln \left(C_{t}\right)+\ln \left(T-\vartheta_{t}\left(h e_{t}+\xi\right)\right)+\frac{\nu}{1-\chi}\left(\frac{M_{t}}{P_{t}}\right)^{1-\chi}
$$

where $T$ is a fixed time endowment and $\vartheta_{t}$ is an indicator variable, equal to one if the worker is employed and providing effort and zero otherwise. The parameter $\xi$ measures fixed costs incurred from exerting any positive level of effort. The variable $C_{t}$ is a composite good assembled using a $[0,1]$ continuum of differentiated products. It takes on a value of $C_{t}^{u}$ if the individual is unemployed, $C_{t}^{s}$ if the individual is identified as a shirker, and $C_{t}^{e}$ otherwise.

Imperfect monitoring creates a moral hazard problem in the workplace, as members can decide whether or not to abide by the terms of the contract after job offers are accepted. ${ }^{4}$ Alexopoulos (2006a) demonstrates that workers in this situation provide the mandatory effort only if the ensuing utility is greater than or equal to the expected utility associated with shirking. Otherwise, they exert zero effort. This means that firms can prevent shirking provided the job contract is incentive compatible, that is, only if the following constraint is satisfied:

$$
U\left(C_{t}^{e}, e_{t}, \frac{M_{t}}{P_{t}}\right) \geq d U\left(C_{t}^{s}, 0, \frac{M_{t}}{P_{t}}\right)+(1-d) U\left(C_{t}^{e}, 0, \frac{M_{t}}{P_{t}}\right)
$$

\subsubsection{The Representative Family's Problem}

The family's objective is to maximize the expected discounted value of the average utility of its members. In the next section I show that job contracts are incentive compatible, ensuring that working members will not shirk. Thus, family preferences can be summarized by

$$
E_{0} \sum_{t=0}^{\infty} \beta^{t}\left[N_{t} U\left(C_{t}^{e}, e_{t}, \frac{M_{t}}{P_{t}}\right)+\left(1-N_{t}\right) U\left(C_{t}^{u}, 0, \frac{M_{t}}{P_{t}}\right)\right] .
$$

\footnotetext{
${ }^{4}$ Families observe which members receive job offers and unemployment benefits are denied to anyone who rejects an offer. This ensures that all offers are accepted and that unemployment will be strictly involuntary.
} 
The family selects $\left\{C_{t}^{f}, B_{t+1}, M_{t}\right\}_{t=0}^{\infty}$ to maximize (8) subject to (1), (2), and (4), taking as given $B_{0}, M_{-1}$, and sequences $\left\{N_{t}, e_{t}, P_{t}, Q_{t, t+1}, T_{t}, w_{t}, f_{t}, D i v_{t}(i): i \in[0,1]\right\}_{t=0}^{\infty}$.

The first-order conditions with respect to family consumption, bonds, and money are

$$
\begin{gathered}
\lambda_{t}=N_{t} \frac{1}{C_{t}^{e}}+\left(1-N_{t}\right) \frac{1}{C_{t}^{u}}, \\
\lambda_{t}=\beta R_{t} E_{t}\left[\frac{\lambda_{t+1}}{\pi_{t+1}}\right], \\
\lambda_{t}=\beta E_{t}\left[\frac{\lambda_{t+1}}{\pi_{t+1}}\right]+\nu m_{t}^{-\chi},
\end{gathered}
$$

where $\lambda_{t}$ denotes the Lagrange multiplier associated with $(1), \pi_{t}$ is the gross inflation rate, and $m_{t}$ measures holdings of real money balances. ${ }^{5}$

\section{$2.2 \quad$ Firms}

There are two groups of firms. The first group produces a homogeneous final good sold in competitive markets. The second consists of monopolistically competitive firms that hire family members to manufacture differentiated inputs for the production of the final good.

\subsubsection{Final Good Firms}

A competitive firm produces a final good $Y_{t}$ by assembling a continuum of intermediate goods indexed by $i \in[0,1]$ using a Dixit-Stiglitz (1977) technology

$$
Y_{t}=\left[\int_{0}^{1} Y_{t}(i)^{\frac{1}{1+\eta}} d i\right]^{1+\eta} \quad \eta>0 .
$$

\footnotetext{
${ }^{5}$ To derive (10) I apply the result that $E_{t}\left[Q_{t, t+1}\right]$ equals the price of an asset that pays one unit of currency in every state of period $t+1$, or equivalently, the inverse of the risk-free nominal interest rate $R_{t}$.
} 
$Y_{t}(i)$ denotes the quantity of good $i$ and $\eta$ reflects the demand elasticity for alternative goods. The firm's derived demand for good $i$ is given by

$$
Y_{t}(i)=\left[\frac{P_{t}(i)}{P_{t}}\right]^{-\frac{1+\eta}{\eta}} Y_{t},
$$

where $P_{t}(i)$ is the date- $t$ price of $Y_{t}(i)$. Zero profit ensures that the final good price depends on the intermediate good prices in the following way:

$$
P_{t}=\left[\int_{0}^{1} P_{t}(i)^{-\frac{1}{\eta}} d i\right]^{-\eta} .
$$

\subsubsection{Intermediate Good Firms}

Differentiated goods are produced using the technology

$$
Y_{t}(i)=\left[n_{t}(i)-n_{t}^{s}(i)\right] h e_{t}(i)
$$

where $e_{t}(i)$ is the effort level required by firm $i$, and $n_{t}(i)$ and $n_{t}^{s}(i)$ denote the measure of employees and shirkers hired in period $t$, respectively. Because firms pay a fraction of the wage bill up front, it is never cost-effective to hire shirkers. As a result, they negotiate job contracts specified by an effort-wage pair $\left\{e_{t}(i), w_{t}(i)\right\}$ that induces effort on the part of all employees.

Formally, firms choose a triplet $\left\{n_{t}(i), e_{t}(i), w_{t}(i)\right\}$ to minimize the period- $t$ real unit cost of production $w_{t}(i) n_{t}(i) h$ subject to $n_{t}(i) h e_{t}(i) \geq 1$ and the incentive compatibility constraint (7). The latter constraint binds in equilibrium as firms find it optimal to make workers indifferent between providing the requisite effort and shirking. Using (2), (3), and (6), one can rearrange (7) to express effort as a function of the wage, the family consumption 
benefit, and the insurance fee.

$$
e_{t}(i)=e\left(w_{t}(i)\right)=\frac{T-\xi}{h}-\frac{T}{h}\left(\frac{C_{t}^{f}+h w_{t}(i)-f_{t}}{C_{t}^{f}+s h w_{t}(i)-f_{t}}\right)^{-d}
$$

Subject to (16), cost minimization yields the first-order condition

$$
\frac{w_{t}(i) e^{\prime}\left(w_{t}(i)\right)}{e\left(w_{t}(i)\right)}=1
$$

which states that at the optimum, the elasticity of effort with respect to the real wage is unity. ${ }^{6}$ The wage satisfying (17), often referred to as an efficiency wage in the literature, is higher than the one that would prevail in the absence of imperfect monitoring. The failure of markets to clear in the traditional Walrasian sense generates unemployment in equilibrium.

By taking the derivative of (16) with respect to the real wage and substituting the resulting expression into (17), one can show that the ratio $C_{t}^{e} / C_{t}^{s}$ is constant in equilibrium. Moreover, that constant solves the nonlinear equation

$$
\operatorname{Td}(1-s \tilde{C})(\tilde{C}-1)=(1-s)\left[(T-\xi) \tilde{C}^{1+d}-T \tilde{C}\right]
$$

where $\tilde{C} \equiv C_{t}^{e} / C_{t}^{s}$. Finally, substituting $\tilde{C}$ into (16) implies

$$
e_{t}(i)=e=\frac{T-\xi}{h}-\frac{T}{h} \tilde{C}^{-d}
$$

illustrating that the incentive compatible level of effort is constant through time and identical across firms. The fact that producers share a common technology also ensures that the optimal wage satisfying (17) is the same for each.

Although employment contracts are formed on a period-by-period basis, price contracts

\footnotetext{
${ }^{6}$ Firms treat the family's insurance arrangement parametrically when minimizing production costs.
} 
are not. Following Taylor (1980) and CKM (2000), I assume that producers belong to one of $X$ discrete groups. Each group locks in a price for $X$ periods at a time and does so in an overlapping fashion. Firms are catalogued according to the following rule: producers $i \in[0,1 / X]$ reset prices during periods $0, X, 2 X, \ldots$, while producers $j \in[1 / X, 2 / X]$ reset prices during periods $1, X+1,2 X+1, \ldots$, and so on for the $X$ distinct cohorts. Subject to the demand condition (13), firm $i \in[0,1 / X]$ selects its price at date $t$ to maximize the expected discounted value of real profits over the duration of the contract given by

$$
E_{t-1} \sum_{j=0}^{X-1} Q_{t, t+j} Y_{t+j}(i)\left[\frac{P_{t}(i)}{P_{t+j}}-m c_{t+j}\right]
$$

where $m c_{t}$ denotes the real marginal cost of production in period $t$. In the benchmark model, $m c_{t}=w_{t} / e$ since it is optimal for firms to elicit constant effort. The conditional expectations operator $E_{t-1}$ reflects the assumption that firms must set prices before the period- $t$ realization of the monetary shock.

The first-order necessary condition for this problem can be written as

$$
P_{t}^{*} E_{t-1} \sum_{j=0}^{X-1} Q_{t, t+j}\left[\prod_{\tau=1}^{j} \pi_{t+\tau}\right]^{\frac{1}{\eta}} Y_{t+j}=(1+\eta) E_{t-1} \sum_{j=0}^{X-1} Q_{t, t+j}\left[\prod_{\tau=1}^{j} \pi_{t+\tau}\right]^{\frac{1+\eta}{\eta}} Y_{t+j} m c_{t+j}
$$

where $P_{t}^{*} \equiv P_{t}(i) / P_{t}$ denotes the relative contract price common to all firms adjusting in period $t .^{7}$ The price index (14) implies that the intermediate and final good prices satisfy

$$
1=\frac{1}{X} \sum_{j=0}^{X-1}\left(P_{t-j}^{*} \prod_{\tau=0}^{j-1} \pi_{t-\tau}^{-1}\right)^{-\frac{1}{\eta}}
$$

\footnotetext{
${ }^{7}$ One can show using (10) that the stochastic discount factor satisfies $Q_{t, t+j}=\beta^{j} \frac{\lambda_{t+j}}{\lambda_{t}}\left(\prod_{\tau=1}^{j} \pi_{t+\tau}^{-1}\right)$.
} 


\subsubsection{The No-shirking Condition}

Imperfect monitoring adds a non-Walrasian element that transforms the nature of the labor market. In the language of Shapiro and Stiglitz (1984), a "no-shirking condition" emerging from the incentive compatibility constraint replaces the traditional Walrasian labor supply curve appearing in most models. Together with a demand function reflecting productivity, the no-shirking condition pins down the equilibrium wage and level of employment.

To derive the no-shirking condition, use (2), (3), and the result that $C_{t}^{e} / C_{t}^{s}$ is constant in equilibrium to obtain

$$
h w_{t}=\frac{1}{1-s}\left(\frac{\tilde{C}-1}{\tilde{C}}\right) C_{t}^{e} .
$$

For a fixed level of family consumption $C_{t}^{f}$, the no-shirking condition (23) establishes a positive relationship between $w_{t}$ and $N_{t}$. According to (5), the insurance fee $f_{t}$ falls as employment rises, elevating $C_{t}^{e}$ and, hence, the real wage.

In addition to describing the labor market, the no-shirking condition ensures that the consumption ratio between the employed and the unemployed is fixed in equilibrium. To see how, first use (2) and (5) to eliminate $C_{t}^{f}$ and $f_{t}$ from (4). Next, substitute out the real wage by using (23). What remains is a proportional relationship between $C_{t}^{e}$ and $C_{t}^{u}$

$$
\frac{C_{t}^{u}}{C_{t}^{e}}=\mu(\sigma) \equiv 1-\frac{1-\sigma}{1-s}\left(\frac{\tilde{C}-1}{\tilde{C}}\right)
$$

where $\mu$ is a positive constant bounded above by one and increasing in the degree of income insurance $\sigma$. The value of $\mu$ fully characterizes the extent of risk sharing among family members, and in simulation exercises, plays a critical role in shaping the model's dynamic response to a monetary shock. 


\subsection{The Monetary Authority}

Denote $\Theta_{t} \equiv M_{t} / M_{t-1}$ the growth rate of the money stock. The monetary authority conducts policy by setting the growth rate according to the rule

$$
\ln \Theta_{t}=(1-\rho) \ln \Theta+\rho \ln \Theta_{t-1}+\varepsilon_{t} \quad \rho \in[0,1)
$$

where $\Theta \geq 1$ is the average value of $\Theta_{t}$ and $\varepsilon_{t}$ is a mean-zero, serially uncorrelated shock with unit variance. ${ }^{8}$ The money growth rate is linked to current and past real balances and inflation by the identity

$$
\Theta_{t}=\frac{m_{t}}{m_{t-1}} \pi_{t}
$$

\subsection{Equilibrium}

Equilibrium in the final goods market is given by

$$
Y_{t}=N_{t} C_{t}^{e}+\left(1-N_{t}\right) C_{t}^{u}
$$

Equilibrium in the intermediate sector requires market clearing for each good variety.

$$
n_{t}(i) e h=\left[\frac{P_{t}(i)}{P_{t}}\right]^{-\frac{1+\eta}{\eta}} Y_{t} \quad \forall i \in[0,1]
$$

Integrating (28) reveals that aggregate output and employment satisfy the relationship

$$
N_{t} e h=\Delta_{t} Y_{t}
$$

where $N_{t} \equiv \int_{0}^{1} n_{t}(i) d i$ and $\Delta_{t} \equiv \int_{0}^{1}\left[\frac{P_{t}(i)}{P_{t}}\right]^{-\frac{1+\eta}{\eta}} d i$.

The variable $\Delta_{t}$ summarizes the output loss from inefficient price dispersion that occurs

\footnotetext{
${ }^{8}$ Monetary injections are engineered via lump-sum transfers to the family: $T_{t}=M_{t}-M_{t-1}$.
} 
in the presence of nominal stickiness. Under the specific price-setting rule assumed here, this dispersion term can be written as

$$
\Delta_{t}=\frac{1}{X} \sum_{j=0}^{X-1}\left(P_{t-j}^{*} \prod_{\tau=0}^{j-1} \pi_{t-\tau}^{-1}\right)^{-\frac{1+\eta}{\eta}}
$$

A dynamic equilibrium for the shirking model is a collection of stochastic processes $\left\{\lambda_{t}, N_{t}, C_{t}^{e}, C_{t}^{u}, R_{t}, \pi_{t}, m_{t}, w_{t}, Y_{t}, \Delta_{t}, m c_{t}, P_{t}^{*}, \Theta_{t}\right\}_{t=0}^{\infty}$ satisfying the following: the family's firstorder conditions (9) - (11), the pricing equation (21), the definition of marginal cost, the price index (22), the no-shirking condition (23), the risk-sharing condition (24), the market clearing condition (27), the aggregate relationship (29), the law of motion for price dispersion (30), the money supply relation (26), and the exogenous process for money growth (25).

\subsection{Calibration}

The structural parameters are calibrated to match certain statistical features of the U.S. data and are displayed in Table 1. I assume that the unit of time equals one quarter. The discount factor $\beta$ is set equal to $1.03^{-1 / 4}$ so that the model delivers a steady state annualized mean real interest rate of 3 percent. Following Alexopoulos (2004), I assign to $T$ a value of 1369 hours per quarter and to $\xi$ a value of 16 hours per quarter. This corresponds to an endowment of 15 hours per day with fixed costs of exerting nonzero effort absorbing roughly 10 minutes per day. The shift length $h$ is set equal to one since it has no impact on the dynamics of the model. I fix $\chi=1$, implying unit interest elasticity of money demand. I adjust the scaling coefficient $\nu$ to ensure a steady state consumption-based money velocity of 1.035 per quarter, which corresponds to the average quarterly ratio of personal consumption expenditures to the M1 money stock over the period 1959 - 2005.

For the no-shirking condition, I follow a strategy taken by Alexopoulos (2004) whereby values for $\tilde{C}$ and $s$ are chosen first, and then (18) is used to back out the implied detection 
Table 1: Calibrated Parameter Values in the Benchmark Model

\begin{tabular}{ll}
\hline \hline Preferences: & \\
$\ln (C)+\ln (T-\vartheta(h e+\xi))+\frac{\nu}{1-\chi} m^{1-\chi}$ & $\begin{array}{l}T=1369, \vartheta \in\{0,1\}, h=1 \\
\xi=16, \chi=1, \nu \text { adjusted }\end{array}$ \\
Subjective discount factor & $\beta=1.03^{-1 / 4}$ \\
No-shirking: & \\
$T d(1-s \tilde{C})(\tilde{C}-1)=(1-s)\left[(T-\xi) \tilde{C}^{1+d}-T \tilde{C}\right]$ & $\tilde{C}=1.28535, s=0.74604$ \\
$\mu(\sigma)=1-\frac{1-\sigma}{1-s}\left(\frac{\tilde{C}-1}{\tilde{C}}\right)$ & $\sigma=s, \mu=0.778$ \\
& \\
Price-setting: & $X=4$ \\
Price duration & $\eta=0.20$ \\
Price markup & \\
Money growth: & $\Theta=1.0092, \rho=0.57$ \\
$\ln \Theta_{t}=(1-\rho) \ln \Theta+\rho \ln \Theta_{t-1}+\varepsilon_{t}$ & \\
\hline \hline
\end{tabular}

probability $d$. Based on the evidence reported in Gruber (1997) that temporary unemployment reduces food consumption by 22.2 percent, I select a value of 1.28535 for $\tilde{C}$. For this measure to translate into the model, I initially set $\sigma=s$ to ensure that $\tilde{C}$ corresponds to $C_{t}^{e} / C_{t}^{u}$ in equilibrium. I subsequently vary $\sigma$ to examine the sensitivity of output dynamics to the degree of risk sharing. Finally, I set $s=0.74604$ so that $N$ equals 0.941 , the mean U.S. employment rate over the period 1959 - 2005.

Regarding price-setting parameters, I fix $\eta=0.20$ so that the markup of prices over marginal cost is 20 percent in the steady state (e.g., Basu and Fernald (1997)). I set $X$ equal to 4 , meaning that in a given quarter, one-fourth of all firms reset prices which are then fixed for one year. This value implies a frequency of price changes that is consistent with estimates obtained in models featuring asynchronous nominal adjustment of the Calvo (1983) variety (e.g., Christiano, Eichenbaum, and Evans (2005) and Rabanal and Rubio-Ramirez (2005)).

As for the money supply process, I set $\Theta$ equal to 1.0092 to deliver steady state inflation of 3.68 percent per annum. This value equals the annualized mean growth rate of the GDP 
deflator from 1959 - 2005. I fix $\rho=0.57$ to match the estimate obtained by CKM (2000).

\section{Results for the Benchmark Model}

In this section I assess the dynamic properties of the shirking model. To gain insight into the effects of incomplete insurance, I start by examining a simplified version of the benchmark economy for which analytical solutions are available. I then go on to conduct stochastic simulations of the fully articulated model described in the previous section.

\subsection{An Illustrative 2-Period Example}

Following CKM (2000), I derive analytical solutions to a version of the model that is simplified along two dimensions. First, there are only two groups of firms $(X=2)$ that set prices for two periods at a time. Second, the law of motion for $\Theta_{t}$ implies that the logarithm of the money supply follows a random walk $(\rho=0$ and $\Theta=1)$. A shock to the growth rate in this case represents a one-time permanent rise in the money supply.

To measure the impact of money supply shocks on the economy, I log-linearize the equilibrium conditions around a deterministic steady state. The approximations to (9) - (11), (24), (27), and (29) jointly imply

$$
\left[\hat{Y}_{t}+\bar{\mu} \hat{P}_{t}\right]=\beta E_{t}\left[\hat{Y}_{t+1}+\bar{\mu} \hat{P}_{t+1}\right]+(1-\beta) \bar{\mu} \hat{M}_{t}
$$

where $\hat{x}_{t}$ denotes the logarithmic deviation of a variable $x_{t}$ from its steady state value. This

is a difference equation in $\left[\hat{Y}_{t}+\bar{\mu} \hat{P}_{t}\right]$ with exogenous forcing process given by $\hat{M}_{t}$. Forward substitution of (31) delivers the stable solution

$$
\hat{Y}_{t}=\bar{\mu}\left(\hat{M}_{t}-\hat{P}_{t}\right),
$$


where the coefficient $\bar{\mu}$ is given by

$$
\bar{\mu} \equiv \frac{\mu+(1-\mu)^{2} N^{2}[1 / N-1]}{\mu+(1-\mu)^{2} N^{2}} .
$$

Recall that firms set prices before observing the date- $t$ monetary disturbance, ensuring that $\hat{P}_{t}$ is unaffected in the impact period. It follows that a one-percent increase in the money supply causes an immediate $\bar{\mu}$-percent increase in output. This result makes clear that the scope of the family's risk sharing arrangement summarized by the value of $\mu$ will have an effect on the amplitude of the monetary business cycle, persistence notwithstanding. Equation (33) indicates that $\bar{\mu}=1$ when workers are fully insured $(\mu=1)$, meaning that a one-percent increase in the money supply is accompanied by a one-percent increase in real output upon impact. Under partial insurance, however, output initially moves less than one-for-one with the money supply since $\bar{\mu}<1$ for $\mu<1 .^{9}$ To be precise, $\bar{\mu}$ is an increasing function of the consumption ratio $\mu$ for most values in its domain, implying that the magnitude of output responses diminish as insurance coverage falls. ${ }^{10}$ I evaluate the quantitative significance of this effect and provide some intuition in the following section.

While the insurance program has a direct impact on the size of non-neutralities, the emergence of output persistence depends critically on how much prices respond in the periods following a shock. To examine price behavior, combine the approximations to the no-shirking condition (23), the aggregate relationship (29), and the market clearing condition (27). What follows is an equation linking output to the real wage given by

$$
\hat{w}_{t}=\frac{\mu}{(1-\mu) N+\mu} \hat{Y}_{t} .
$$

\footnotetext{
${ }^{9}$ Note that $N \geq 1 / 2$ is needed to ensure $\bar{\mu} \leq 1$. For the parameter variations considered here, the steady state employment rate never deviates too far from the initial calibration.

${ }^{10}$ The function $\bar{\mu}(\mu)$ actually rises slightly as $\mu$ gets very close to its lower bound. I demonstrate this numerically in the next section rather than derive $\bar{\mu}^{\prime}$ analytically. The expression turns out to be complicated and largely uninformative since the steady state employment rate $N$ is itself a nontrivial function of $\mu$.
} 
This relationship indicates to what extent changes in economic conditions impact real wages and, hence, marginal cost. When $\mu=1$ a percent change in output is matched by an equivalent percent change in the real wage, illustrating the highly procyclical nature of marginal cost under a perfect risk sharing arrangement. This is precisely the feature that CKM (2000) and others charge as the chief inhibitor of persistence in standard New Keynesian models. Incomplete risk sharing $(\mu<1)$, on the other hand, clearly dampens the sensitivity of real wages to fluctuations in output, boosting the amount of endogenous wage rigidity present in the model. A drop in the elasticity of marginal cost, in turn, motivates firms to administer smaller price adjustments in the ensuing periods, leading to greater output persistence in the aftermath of a nominal disturbance.

To formalize the impact of limited insurance on output dynamics, combine (34) with the approximation to the pricing equation (21). Next, use (32) to eliminate output from the resulting expression, and approximate (22) to rewrite the final good price in terms of the two prevailing contract prices. What remains is a second-order difference equation given by

$$
\beta E_{t-1} \hat{\bar{P}}_{t+1}-\frac{(1+\beta)(1+\tilde{\mu} \bar{\mu})}{(1-\tilde{\mu} \bar{\mu})} \hat{\bar{P}}_{t}+\hat{\bar{P}}_{t-1}=-\frac{2 \tilde{\mu} \bar{\mu}}{1-\tilde{\mu} \bar{\mu}} E_{t-1}\left[\hat{M}_{t}+\beta \hat{M}_{t+1}\right]
$$

where $\tilde{\mu} \equiv \frac{\mu}{(1-\mu) N+\mu}$ and $\hat{\bar{P}}_{t}$ denotes the logarithm of the price chosen by firms optimizing at date $t .{ }^{11}$ Applying familiar techniques to solve $(35)$ for $\beta \approx 1$ yields

$$
\hat{\bar{P}}_{t}=a \hat{\bar{P}}_{t-1}+\frac{2 a \tilde{\mu} \bar{\mu}}{1-\tilde{\mu} \bar{\mu}} E_{t-1} \sum_{j=0}^{\infty} a^{j}\left[\hat{M}_{t+j}+\hat{M}_{t+j+1}\right]
$$

where $a$ is the root with absolute value less than one that solves the characteristic equation

\footnotetext{
${ }^{11}$ In terms of the optimal relative contract price and the average price level, $\hat{\bar{P}}_{t}=\hat{P}_{t}^{*}+\hat{P}_{t}$.
} 
$a^{2}-\frac{2(1+\tilde{\mu} \bar{\mu})}{(1-\tilde{\mu} \bar{\mu})} a+1=0$. That root is given by

$$
a=\frac{1-\sqrt{\tilde{\mu} \bar{\mu}}}{1+\sqrt{\tilde{\mu} \bar{\mu}}}
$$

Recognizing that $\hat{M}_{t}$ follows a random walk leads to the reduced-form expression

$$
\hat{\bar{P}}_{t}=a \hat{\bar{P}}_{t-1}+(1-a) \hat{M}_{t-1}
$$

Finally, (32) and (38) jointly imply

$$
\hat{Y}_{t}=a \hat{Y}_{t-1}+\bar{\mu} \varepsilon_{t}+\frac{1}{2}(1-a) \bar{\mu} \varepsilon_{t-1}
$$

Inspection of (38) and (39) reveals that the autoregressive parameter $a$ determines the magnitude of output persistence as well as the degree of sluggishness in the contract price. Specifically, output becomes more persistent as a rises, and the contract price displays smaller, albeit more persistent, fluctuations after a money supply shock. Following Bergin and Feenstra (2000), I formally measure endogenous persistence as the fraction of the impactperiod output departure that still remains after all firms have had a chance to adjust their price in response to the shock. Because the duration of price fixity is two periods, endogenous persistence in the simplified model is $a(1+a) / 2$. It follows that what is needed to generate positive persistence is $a>0$, which according to (37), will be satisfied as long as $\tilde{\mu} \bar{\mu}<1$.

The product $\tilde{\mu} \bar{\mu}$ can be expressed as

$$
\tilde{\mu} \bar{\mu}(\mu)=\frac{\mu-\mu(1-\mu) N}{\mu+(1-\mu)^{2} N^{2}}
$$

which is a monotone increasing function of the risk sharing parameter $\mu$. Notice that $\tilde{\mu} \bar{\mu}(1)=$ 1 under a perfect insurance arrangement. In this case $a=0$ and the model fails to deliver 
endogenous persistence. The contract price responds fully to an increase in the money supply one period later, ensuring that output departures completely dissipate by the time all firms have responded to the shock. In the case of partial insurance, however, $\tilde{\mu} \bar{\mu}(\mu<1)<1$, resulting in $a \in(0,1)$. This finding makes clear that imperfect risk sharing is the key mechanism enabling the model to deliver output responses that survive after all existing price contracts expire. In fact, the size of endogenous persistence and the degree of sluggishness in the contract price both increase as insurance opportunities narrow. I explore the quantitative significance of this relationship and discuss the intuition in the next section.

\subsubsection{Comparison to a Walrasian Model}

Although the central focus here is on the impact of partial insurance, the presence of unobservable effort alone helps boost persistence relative to a model with a purely Walrasian treatment of the labor market. In a variant of the CKM (2000) model where preferences are separable and logarithmic in consumption, the law of motion for output becomes

$$
\hat{Y}_{t}=b \hat{Y}_{t-1}+\varepsilon_{t}+\frac{1}{2}(1-b) \varepsilon_{t-1}
$$

where $b=\frac{1-\sqrt{1+\gamma}}{1+\sqrt{1+\gamma}}$ and $\gamma \geq 0$ is the inverse wage elasticity of labor supply. With finite labor supply elasticity, endogenous persistence is negative since $b<0$ when $\gamma>0$. Thus, the shirking mechanism by itself increases persistence from a negative value to zero under the maintained assumption of perfect risk sharing. If labor supply elasticity becomes large, however, endogenous persistence approaches zero, matching the value obtained by the shirking model. Moreover, a comparison of (39) and (41) reveals that output dynamics are completely identical in this case. ${ }^{12}$ In light of its equivalence to the full insurance version of the shirking model, I choose not to report results from the Walrasian model in the next sections.

\footnotetext{
${ }^{12}$ Alexopoulos (2004) shows that full insurance renders the shirking model observationally equivalent to a standard Walrasian model with utility linear in leisure.
} 


\subsection{Simulations of the Fully Articulated Model}

The figures in Table 2 are from an impulse response analysis under a variety of insurance programs stretching from full coverage $(\mu=1.00)$ to no coverage $(\mu=0.1256)$. The column labeled impact effect measures the initial departure of output after a unit innovation to the money growth rate. Following Dotsey and King (2006), impact elasticity is the ratio of the initial departure of real marginal cost to the impact effect, and total multiplier is the area under the impulse response function for output up to a period of twenty quarters. In concert with the previous discussion, endogenous persistence is defined as the fraction of the impact effect that remains four periods later, that is, after all firms have responded to the shock.

Simulation results bolster the key analytical finding that limiting the amount of insurance increases the persistence of output after a nominal shock. As risk sharing falls from $\mu=1.00$ to $\mu=0.13$, endogenous persistence rises from -0.005 to 0.473 . Greater persistence follows naturally from an accompanying decline in impact elasticity. Over the same interval for $\mu$, impact elasticity falls from 1 to 0.167 , implying that the responsiveness of marginal cost diminishes rapidly as risk sharing opportunities vanish. Smaller fluctuations in marginal cost persuade firms to make smaller price adjustments, increasing the sluggishness of the overall price level and lengthening the response of output. Thus, the mechanism generating persistence in the shirking model operates through a cost-dampening effect that is similar to other recent studies emphasizing various alternative frictions like sticky wages, produced inputs, chain production, variable factor utilization, and increasing returns.

While is it clear that imperfect risk sharing renders the model persistent, relatively modest endogenous persistence of about 5 percent occurs under the benchmark calibration. This parameter choice, however, rests solely on the empirical observation made by Gruber (1997) that, lacking government unemployment compensation, a stretch of unemployment would lower one's food consumption by 22 percent. To the extent that the consumption of services and other nondurables are more sensitive to unemployment spells, one could argue that 0.78 
Table 2: Simulation Results for the Benchmark Model

\begin{tabular}{cllll}
\hline \hline \multirow{2}{*}{ Risk Sharing } & $\begin{array}{l}\text { Impact } \\
\text { Effect }\end{array}$ & $\begin{array}{l}\text { Impact } \\
\text { Elasticity }\end{array}$ & $\begin{array}{l}\text { Total } \\
\text { Multiplier }\end{array}$ & $\begin{array}{l}\text { Endogenous } \\
\text { Persistence }\end{array}$ \\
\hline$\mu=1.00$ & 2.276 & 1.000 & 5.810 & -0.005 \\
$\mu=0.90$ & 2.255 & 0.905 & 5.919 & 0.014 \\
$\mu=0.80$ & 2.185 & 0.809 & 5.950 & 0.039 \\
$\mu=0.78^{\dagger}$ & 2.163 & 0.788 & 5.946 & 0.046 \\
$\mu=0.70$ & 2.062 & 0.714 & 5.892 & 0.073 \\
$\mu=0.60$ & 1.888 & 0.619 & 5.743 & 0.118 \\
$\mu=0.50$ & 1.674 & 0.523 & 5.525 & 0.175 \\
$\mu=0.40$ & 1.443 & 0.428 & 5.291 & 0.246 \\
$\mu=0.30$ & 1.233 & 0.333 & 5.160 & 0.330 \\
$\mu=0.20$ & 1.116 & 0.237 & 5.441 & 0.418 \\
$\mu=0.13^{\dagger \dagger}$ & 1.218 & 0.167 & 6.573 & 0.473 \\
\hline \hline
\end{tabular}

Note: Impact effect measures the initial departure of output following a unit money growth shock. Impact elasticity is the ratio of real marginal cost to output upon impact. Total multiplier is the sum of impulse responses for output up to 20 periods. Endogenous persistence is the fraction of impact effect that survives four periods after the shock occurs. $\dagger$ denotes the consumption ratio consistent with the original calibration. $\dagger \dagger$ denotes the consumption ratio in the absence of unemployment insurance.

constitutes a reasonable upper bound on $\mu$. For intermediate values of risk sharing between 0.70 and 0.30 , endogenous persistence is more substantial, ranging from 7 to 33 percent.

The microeconomic rationale for why partial insurance strengthens persistence is relatively straightforward. Consider a unit rise in employment demand triggered by an increase in the growth rate of money. According to (5), this reduces the intra-family insurance fee $f_{t}$ by an amount $\sigma h w_{t}$ for a fixed real wage. Holding family consumption $C_{t}^{f}$ constant, it follows from (2) and (3) that $C_{t}^{e}$ and $C_{t}^{s}$ rise by equal amounts, that is, by the size of the decline in $f_{t}$. Because detected shirkers encounter a monetary punishment, the percentage rise in $C_{t}^{s}$ is larger than the percentage rise in $C_{t}^{e}$ by assumption. The effect is to depress the $C_{t}^{e} / C_{t}^{s}$ ratio and, hence, the penalty associated with shirking. Other things equal, employees will strictly favor shirking under the existing contract. To elicit the desired effort level, firms elevate the wage to the point where the consumption ratio again reaches $\tilde{C}$. 
Figure 1: Dynamic Responses for the Benchmark Model
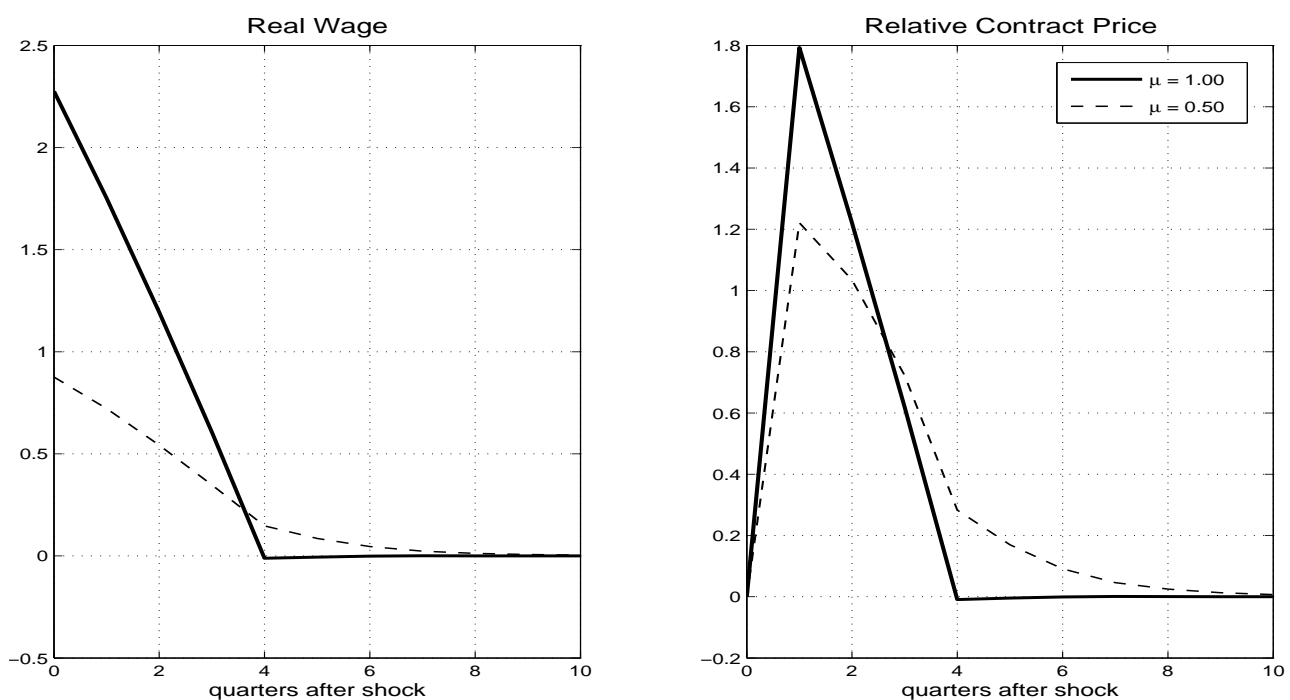

Note: Each panel graphs the impulse response function to a unit increase in the growth rate of money. Variables are measured in percent deviations from a steady state. The solid line $(\mu=1.00)$ corresponds to the full insurance case and the dashed line $(\mu=0.50)$ corresponds to the partial insurance case.

Although the sequence of events just described is invariant to the particular risk sharing arrangement, demand shocks have a smaller effect on the unemployment fee under partial insurance than they do under full insurance since $\sigma<1$ under the former. Thus, the corresponding rise in $C_{t}^{e}$ and $C_{t}^{s}$, while still equal, generates a smaller decline in the $C_{t}^{e} / C_{t}^{s}$ ratio when insurance markets are incomplete. This implies that the real wage adjustment necessary to preserve incentive compatibility diminishes the more limited risk sharing becomes. ${ }^{13}$ Evidence of this effect appears in Figure 1 which graphs the impulse response function for the real wage $\hat{w}_{t}$ and the relative contract price $\hat{P}_{t}^{*}$ for two different values of $\mu$. As risk sharing declines from $\mu=1.00$ to $\mu=0.50$, the wage hike needed to secure positive effort in the impact period falls from 2.28 to 0.86 percent. Consequently, firms that reoptimize in the next period boost prices by only 1.22 percent as opposed to 1.79 percent under full

\footnotetext{
${ }^{13}$ This is essentially the same mechanism that Alexopoulos (2004) credits for the amplified response of output to both technology and fiscal shocks in a flexible price version of the shirking model.
} 
insurance. The dampening of labor cost expansions over the business cycle and the resulting deceleration of prices leads to greater output persistence under partial insurance.

It should be noted that monetary shocks affect the incentive compatibility constraint through a second channel distinct from the insurance fee margin. Specifically, changes in family consumption $C_{t}^{f}$ shift the $C_{t}^{e} / C_{t}^{s}$ ratio, altering workers' incentive to provide effort. The budget constraint (1) makes clear that $C_{t}^{f}$ is equal to family profits in equilibrium. Following a money supply shock, the expansion of marginal cost is usually large enough to trim profit margins. The ensuing fall in $C_{t}^{f}$ lifts the $C_{t}^{e} / C_{t}^{s}$ ratio, raising the penalty for shirking. By the converse of the previous argument, firms will reduce wages until the consumption ratio realigns with $\tilde{C}$. It turns out that for nearly all levels of risk sharing, the insurance fee margin dominates the family consumption margin, ensuring that wages will rise after a monetary shock. ${ }^{14}$ However, this will not always be the case in the model with capital as wages can actually decline for a sufficiently small degree of risk sharing.

Returning to Table 2, simulations confirm the analytical result linking the amplitude of the business cycle to the size of the insurance policy. Notice that impact effect falls from 2.276 to 1.218 percent as wage pooling activity declines. Coupled with the first result, it appears that the absence of complete insurance markets engenders a kind of persistenceamplitude-tradeoff in the shirking model. ${ }^{15}$ The emergence of this dynamic tradeoff can be traced to the impact of employment variation on the family's average marginal utility of consumption as it appears on the right-hand side of (9). Using (24) to substitute for $C_{t}^{u}$, the approximation to (9) can be expressed as

$$
\hat{\lambda}_{t}=\frac{(1-\mu) N}{(1-\mu) N-1} \hat{N}_{t}-\hat{C}_{t}^{e}
$$

\footnotetext{
${ }^{14}$ The insurance fee margin obviously vanishes as $\mu$ approaches its lower bound. Nevertheless, the wage continues to rise because the response of profits and, hence, family consumption is slightly positive for low levels of risk sharing.

${ }^{15}$ As alluded to earlier, impact effect actually rises by a small amount as $\mu$ approaches its lower bound, indicating that the tradeoff does not apply to very small levels of risk sharing.
} 
With full insurance, employment fluctuations leave average marginal utility of consumption unchanged since all members consume identical quantities. This means that a reduction in the marginal utility of wealth $\hat{\lambda}_{t}$ that is initiated by an increase in the money supply translates into an equivalent rise in $\hat{C}_{t}^{e}$, which according to the market clearing condition (27), is accompanied by a parallel increase in $\hat{Y}_{t} \cdot{ }^{16}$ With partial insurance, an increase in employment reduces average marginal utility since the household's utility function is concave and $C_{t}^{e}>C_{t}^{u}$ by assumption. In order to satisfy (42), it follows that the same decrease in $\hat{\lambda}_{t}$ requires more conservative growth in $\hat{C}_{t}^{e}$ and $\hat{N}_{t}$ in the impact period. A smaller rise in employment, in turn, weakens the initial response of output.

\section{A Model with Capital Accumulation}

CKM (2000) demonstrate that inserting capital into a staggered price model can greatly damage the ability to deliver output persistence. In light of this finding, I reexamine the effects of partial insurance when households make endogenous capital decisions. I couch the discussion in terms of a model that features variable capacity utilization in recognition of recent studies showing that greater elasticity of capital services increases persistence (e.g., Christiano et al. (2005) and Dotsey and King (2006)). For a specific parameter choice, however, the model collapses to one with fixed utilization, making the results directly comparable to CKM (2000) and others. Analyzing both cases enables one to assess what role, if any, variable utilization plays in reinforcing the persistence-enhancing effects of imperfect risk sharing. In the interest of brevity, I describe only the key aspects of the model that depart from the benchmark specification.

Denote $K_{t}$ the period- $t$ stock of capital owned by the representative family, the services of

\footnotetext{
${ }^{16}$ The approximations to (10), (11), and (26) jointly imply $\hat{\lambda}_{t}-\hat{\pi}_{t}+\hat{m}_{t-1}=-\left(1-\frac{\beta \rho}{\pi}\right)^{-1} \hat{\theta}_{t}$. With $\hat{\pi}_{t}$ and $\hat{m}_{t-1}$ predetermined, a unit rise in $\hat{\theta}_{t}$ leads to an immediate 2.276 percent decline in $\hat{\lambda}_{t}$ under the benchmark calibration. The size and direction of this response is independent of the particular insurance arrangement.
} 
which are leased to firms at a competitive rental rate $r_{t}^{k}$. The real income stream generated from renting capital is $r_{t}^{k} u_{t} K_{t}$, where $u_{t}$ is the variable capacity utilization rate. Along with profits and government transfers, rental income is used to purchase family consumption benefits, capital investment goods $I_{t}$, and net additions to the stock of bonds and money holdings. In place of (1), the household's flow budget constraint becomes

$$
P_{t}\left(C_{t}^{f}+I_{t}\right)+E_{t}\left[Q_{t, t+1} B_{t+1}\right]+M_{t}=P_{t} r_{t}^{k} u_{t} K_{t}+B_{t}+M_{t-1}+\int_{0}^{1} D_{i v_{t}}(i) d i+T_{t}
$$

The law of motion for the capital stock is given by

$$
K_{t+1}=\left(1-\delta\left(u_{t}\right)\right) K_{t}+I_{t}-\Phi\left[I_{t} / K_{t}-\delta\left(u_{t}\right)\right] K_{t}
$$

where the depreciation function $\delta\left(u_{t}\right)$ satisfies $\delta \in[0,1], \delta^{\prime}>0$, and $\delta^{\prime \prime}>0$. In the spirit of Greenwood, Hercowitz, and Huffman (1988), the restrictions on $\delta$ capture the notion that boosting the utilization rate accelerates the depreciation of capital. The law of motion (44) also incorporates an adjustment cost function $\Phi$ to dampen investment volatility over the business cycle.

Placing capital and variable utilization into the model broadens the set of decision variables in the family's utility maximization problem. Specifically, the household chooses $\left\{C_{t}^{f}, B_{t+1}, M_{t}, I_{t}, K_{t+1}, u_{t}\right\}_{t=0}^{\infty}$ to maximize (8) subject to (43), (44), (2), and (4), taking as given $B_{0}, K_{0}, M_{-1}$, and sequences $\left\{N_{t}, e_{t}, P_{t}, Q_{t, t+1}, T_{t}, r_{t}^{k}, w_{t}, f_{t}, D i v_{t}(i): i \in[0,1]\right\}_{t=0}^{\infty}$. The first-order conditions and all other general equilibrium equations are in the appendix.

Intermediate firms' production technology takes the form

$$
Y_{t}(i)=k_{t}(i)^{\alpha}\left[n_{t}(i) e_{t}(i) h\right]^{1-\alpha}
$$

where $\alpha \in(0,1)$ is the capital share parameter and $k_{t}(i)$ denotes the period- $t$ capital services 
employed by firm $i$. Firm-level capital is related to aggregate capital by $u_{t} K_{t}=\int_{0}^{1} k_{t}(i) d i$. Because it is unprofitable to hire shirkers, firms negotiate wage contracts that elicit effort from employees. Formally, they select $\left\{k_{t}(i), n_{t}(i), e_{t}(i), w_{t}(i)\right\}$ to minimize production costs $r_{t}^{k} k_{t}(i)+w_{t}(i) h n_{t}(i)$ subject to (45) and (7). The outcome mirrors the benchmark model in that the desired effort level is constant in equilibrium and the real wage satisfies the efficiency condition (17). With multiple factors of production, however, real marginal cost becomes

$$
m c_{t}=\left(\frac{r_{t}^{k}}{\alpha}\right)^{\alpha}\left(\frac{w_{t}}{e(1-\alpha)}\right)^{1-\alpha}
$$

Regarding the calibration, I transfer all of the benchmark parameter values over to the expanded model with the exception of one. To obtain a steady state employment rate of 0.941, I reset the parameter $s$ appearing in the no-shirking condition to 0.69424. The capital share of output $\alpha$ is set equal to 0.36 . I fix $\delta=1.1^{1 / 4}-1$, implying an annual depreciation rate of 10 percent. The steady state coefficient $u$ is fixed at 0.814 , which corresponds to the average U.S. capacity utilization rate over the period 1967 - 2005. Based on evidence reported in Basu and Kimball (1997), the elasticity of marginal depreciation cost $\varphi \equiv u \delta^{\prime \prime} / \delta^{\prime}$ is set equal to unity. The case of fixed capacity utilization can be retrieved by setting $\varphi=\infty$. The adjustment cost function takes the quadratic form $\Phi(\cdot)=\phi[I / K-\delta(u)]^{2} / 2$, where $\phi \geq 0$. I vary $\phi$ so that the ratio of investment to output following a money growth shock is exactly 2.3 in the impact period. This parameter choice rests on the VAR estimates reported in Leeper et al. (1996) indicating that the peak response of nonresidential investment to an identified monetary shock is roughly 2.3 times that of output. 
Table 3: Simulation Results for the Model with Capital

\begin{tabular}{ccccc}
\hline \hline Risk Sharing & $\begin{array}{l}\text { Impact } \\
\text { Effect }\end{array}$ & $\begin{array}{l}\text { Impact } \\
\text { Elasticity }\end{array}$ & $\begin{array}{l}\text { Total } \\
\text { Multiplier }\end{array}$ & $\begin{array}{l}\text { Endogenous } \\
\text { Persistence }\end{array}$ \\
\hline A. Fixed Utilization & & & & \\
$\mu=1.00$ & 3.714 & 1.175 & 9.690 & -0.067 \\
$\mu=0.90$ & 3.627 & 1.026 & 9.741 & -0.048 \\
$\mu=0.80$ & 3.358 & 0.877 & 9.484 & -0.017 \\
$\mu=0.78^{\dagger}$ & 3.276 & 0.845 & 9.388 & -0.008 \\
$\mu=0.70$ & 2.937 & 0.728 & 8.965 & 0.033 \\
$\mu=0.60$ & 2.436 & 0.579 & 8.321 & 0.108 \\
$\mu=0.50$ & 1.937 & 0.430 & 7.757 & 0.216 \\
$\mu=0.40$ & 1.502 & 0.281 & 7.575 & 0.366 \\
$\mu=0.30$ & 1.177 & 0.132 & 8.633 & 0.579 \\
$\mu=0.27^{\dagger \dagger}$ & 1.115 & 0.094 & 9.554 & 0.657 \\
& & & & \\
Bariable Utilization & & & & \\
$\mu=1.00$ & 3.714 & 0.698 & 9.621 & -0.021 \\
$\mu=0.90$ & 3.652 & 0.615 & 9.743 & 0.002 \\
$\mu=0.80$ & 3.449 & 0.529 & 9.639 & 0.037 \\
$\mu=0.78^{\dagger}$ & 3.385 & 0.510 & 9.584 & 0.046 \\
$\mu=0.70$ & 3.106 & 0.439 & 9.308 & 0.089 \\
$\mu=0.60$ & 2.658 & 0.345 & 8.838 & 0.167 \\
$\mu=0.50$ & 2.170 & 0.247 & 8.432 & 0.277 \\
$\mu=0.40$ & 1.712 & 0.144 & 8.572 & 0.434 \\
$\mu=0.30$ & 1.350 & 0.036 & 12.131 & 0.720 \\
$\mu=0.27^{\dagger \dagger}$ & 1.277 & 0.007 & 20.429 & 0.932 \\
\hline \hline
\end{tabular}

Note: Impact effect measures the initial departure of output following a unit money growth shock. Impact elasticity is the ratio of real marginal cost to output upon impact. Total multiplier is the sum of impulse responses for output up to 20 periods. Endogenous persistence is the fraction of impact effect that survives four periods after the shock occurs. $\dagger$ denotes the consumption ratio consistent with the original calibration. $+\dagger$ denotes the consumption ratio in the absence of unemployment insurance. 


\subsection{Simulation Results}

The values reported in panel A of Table 3 indicate that the addition of capital with fixed utilization alters to some degree the risk-persistence relationship. The shirking model now fails to deliver endogenous persistence for values of $\mu$ between 0.78 and 1.00 . I trace this departure from the benchmark outcome to the influence of the real rental rate on the cyclical behavior of marginal cost. Figure 2 graphs the impulse response function for a number of variables under two different values of $\mu$. With full insurance, investment $\hat{I}_{t}$ jumps by 8.54 percent and the rental rate $\hat{r}_{t}^{k}$ by 8.08 percent in the impact period, precipitating a sharp rise in marginal cost of 4.37 percent. Firms naturally accelerate price increases in subsequent periods (the first responders raise prices by 2.13 percent), triggering a significant drop in the demand for their goods. Just four periods later, investment demand falls to 0.89 percent below the steady state, lowering the degree of endogenous persistence relative to the benchmark case.

Simulations reveal that capital does not preclude persistence when risk sharing is sufficiently low. Intermediate values of $\mu$ spanning 0.70 to 0.30 yield endogenous persistence in the neighborhood of 3 to 58 percent. The rapid growth in persistence over this interval reflects a general decline in the sensitivity of both factor prices to changes in economic conditions. Like the benchmark model, less insurance coverage reduces the size of wage adjustments needed to satisfy the incentive compatibility constraint after a demand shock. This same effect also tapers movements in the rental rate. To see why, combine the approximation to (46) with equations (A.29) and (A.33) from the appendix. What remains is an equilibrium relationship linking output, the real wage, and the rental rate given by

$$
\hat{r}_{t}^{k}=\hat{w}_{t}+\frac{1}{1-\alpha}\left[\left(\hat{Y}_{t}+\hat{\Delta}_{t}\right)-\left(\hat{u}_{t}+\hat{K}_{t}\right)\right]
$$

As the value of $\mu$ shrinks, the response of $\hat{w}_{t}$ as well as the impact effect on $\hat{Y}_{t}$ diminish for 
Figure 2: Dynamic Responses for the Model with Capital (Fixed Utilization)
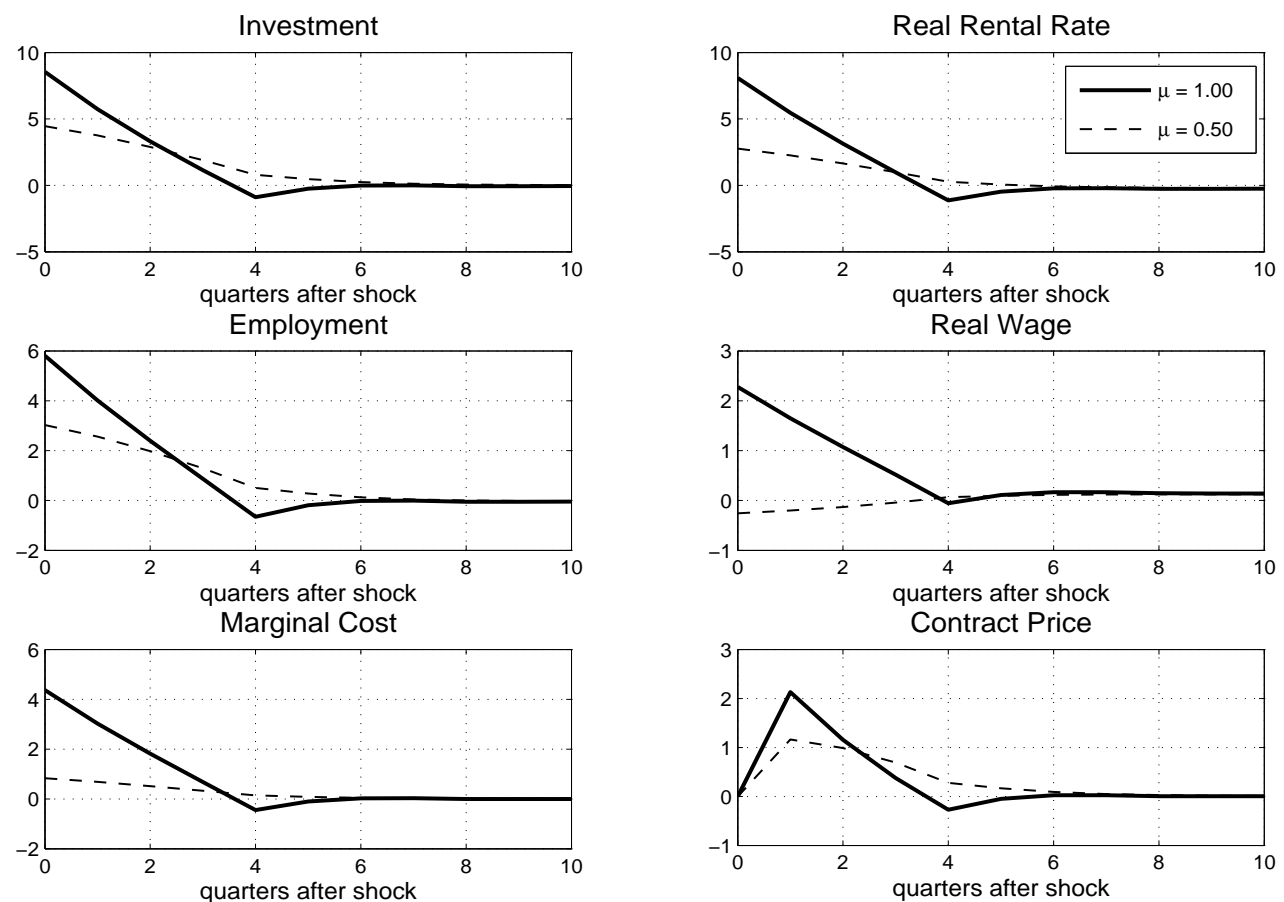

Note: Each panel graphs the impulse response function to a unit increase in the growth rate of money. Variables are measured in percent deviations from a steady state. The solid line $(\mu=1.00)$ corresponds to the full insurance case and the dashed line $(\mu=0.50)$ corresponds to the partial insurance case.

reasons discussed in the previous section. Since $\hat{\Delta}_{t}$ is predetermined and fluctuations in $\hat{K}_{t}$ are small, less risk sharing clearly dampens the adjustment of the rental rate. ${ }^{17}$

Returning to Figure 2, notice that investment climbs by only 4.45 percent and the rental rate by only 2.77 percent when $\mu=0.50$. Moreover, the real wage initially falls by a modest 0.26 percent in contrast to the benchmark case. As indicated earlier, wages fall after a money growth shock because the effect of reduced family consumption on the incentive compatibility constraint now outweighs the reverse effect of smaller unemployment fees. Taken together, the sluggish behavior of both factor prices stemming from progressively fewer insurance

\footnotetext{
${ }^{17}$ With reference to (A.33), the presence of $\hat{w}_{t}$ in (47) reflects the impact of marginal cost on $\hat{r}_{t}^{k}$, and $\hat{Y}_{t}$ reflects the impact of changes in the marginal product of capital services.
} 
Figure 3: Dynamic Responses for the Model with Capital (VARiable Utilization)
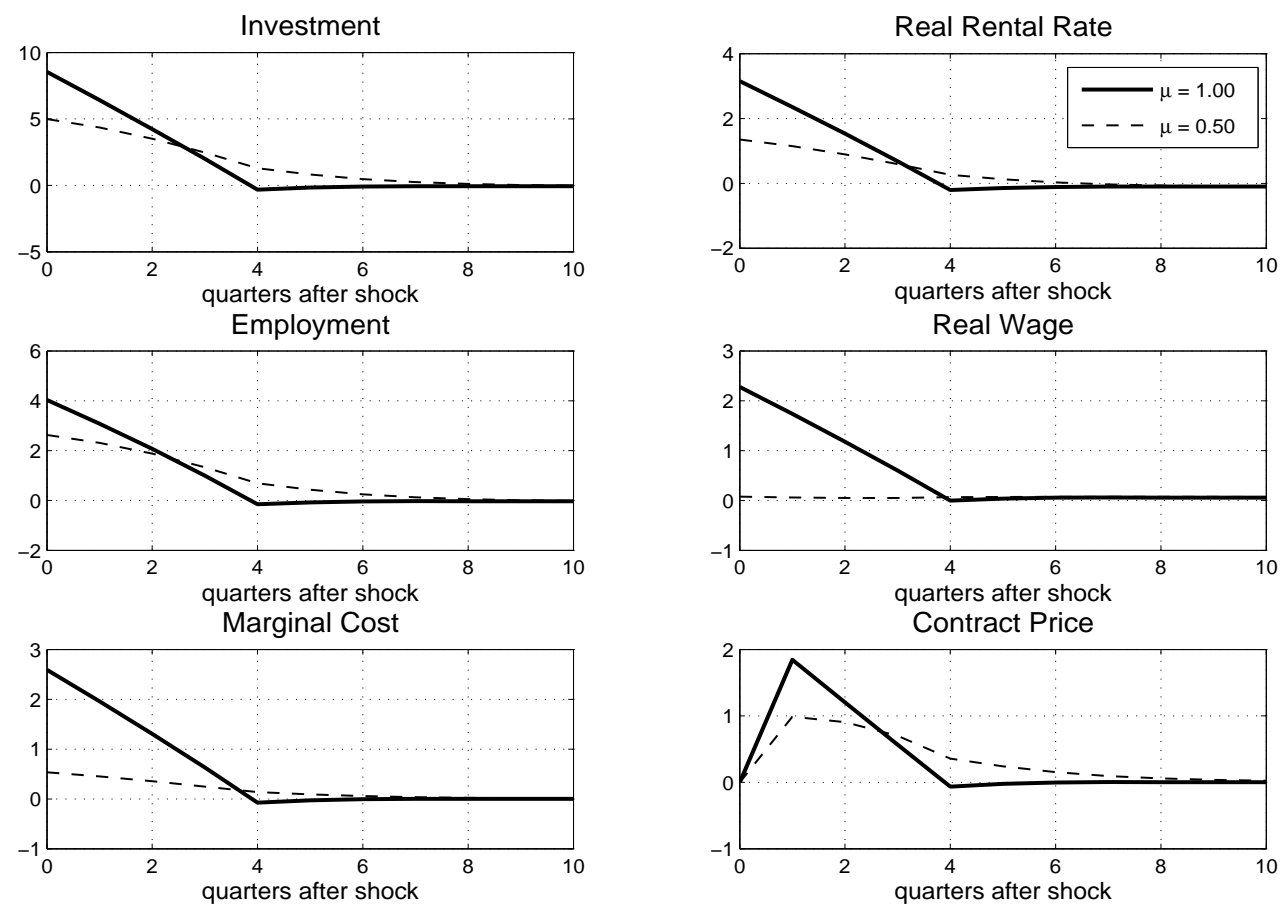

Note: Each panel graphs the impulse response function to a unit increase in the growth rate of money. Variables are measured in percent deviations from a steady state. The solid line $(\mu=1.00)$ corresponds to the full insurance case and the dashed line $(\mu=0.50)$ corresponds to the partial insurance case.

opportunities weakens the sensitivity of marginal cost. As a result, adjustments in the contract price become more inertial, lengthening the duration of output persistence.

The results in panel $\mathrm{B}$ demonstrate that incorporating variable capacity utilization restores output persistence for all values of $\mu$ considered excluding unity. In comparison to the benchmark model, endogenous persistence is now larger for all consumption ratios below $\mu=0.78$, but basically unchanged otherwise. For small enough levels of risk sharing, well over 50 percent of the impact effect still survives one year after the shock. These findings suggest that variable utilization reinforces the persistence-enhancing effects of partial insurance. 
As is well known in the literature, making capital services elastic flattens the marginal cost schedule by muffling the response of the rental rate. This is evident in equation (47) which shows that increasing $\hat{u}_{t}$ mitigates fluctuations in $\hat{r}_{t}^{k}$ for a given response of $\hat{w}_{t}$ and $\hat{Y}_{t}$. A more precise look at the adjustment of $\hat{r}_{t}^{k}$ can be found in Figure 3, which plots the impulse response functions for the same set of variables appearing in Figure 2 under the assumption of variable utilization. With full insurance, $\hat{r}_{t}^{k}$ jumps by only 3.15 percent, about 2.5 times less than in the absence of variable utilization. When $\mu=0.50$, the adjustment is an even smaller 1.35 percent. The paths of the remaining variables are qualitatively similar to the previous experiment.

Returning to Table 3, the comprehensive impact on marginal cost can be ascertained by comparing impact elasticity across both panels. For all levels of risk sharing, impact elasticity falls by approximately 40 percent relative to the the fixed utilization case. Thus, firms attenuate future price increases even more which leads to greater endogenous persistence. As a source of output persistence, I conclude that partial unemployment insurance is generally robust to the inclusion of capital and strengthened by the presence of variable capacity utilization.

\section{Concluding Remarks}

Recent work by CKM (2000) demonstrates that equilibrium models with sticky prices alone are incapable of generating real effects of a monetary shock that persist beyond the exogenously imposed term of price fixity. They conclude that the persistence problem is a direct consequence of the highly sensitive nature of real marginal cost to changes in economic conditions. This discovery commenced a new line of research centered on developing mechanisms capable of enriching the internal propagation of shocks by dampening adjustments in marginal cost. The present study adds to this body of work by assessing the role of 
partial unemployment insurance in boosting output persistence. To provide a rationale for risk sharing behavior, I construct a quantitative business cycle model that gives prominence to a labor market characterized by efficiency wages of the shirking variety.

Unemployment insurance influences the shape of output dynamics through the wagesetting mechanism. Because firms cannot perfectly monitor effort, wages are governed largely by the incentive compatibility constraint of employees. In general, limiting the scope of insurance coverage reduces the sensitivity of real wages to economic forces that alter the incentive compatibility constraint. This feature assures a muted response of marginal cost to demand variation, eliciting more gradual price adjustment and amplifying the persistence of real activity.

In simulation exercises, I find that the model fails to deliver endogenous persistence under a perfect risk sharing arrangement. Conversely, insurance plans that provide the unemployed with no greater than 70 percent of the consumption enjoyed by working members generate at the very least a moderate amount of persistence. With little insurance, the model returns substantial persistence, indicating that output dynamics are rather sensitive along this dimension. I also find that including capital does not significantly damage the ability of imperfect risk sharing to impart persistence while the presence of variable capacity utilization appears to reinforce it.

Although partial insurance strengthens the propagation of monetary shocks, it should not be interpreted as a panacea for staggered price models. Simulations reveal that endogenous persistence is a modest 5 percent under the benchmark calibration. Certainly other important mechanisms are needed to fully replicate the degree of persistence evident in the data, but I choose to ignore them here so as to isolate the effect of partial insurance. I have also focused almost exclusively on the dynamics of real output in this paper. To capture the salient features of the broader data, a richer framework incorporating additional frictions and multiple sources of uncertainty is needed. I leave this task for future research. 


\section{Appendix A. The Model with Capital Accumulation}

This appendix presents the full set of general equilibrium conditions for the shirking model with capital. The model is identical to the benchmark model of Section 2 with a few modifications. First, intermediate goods production requires the use of both labor and capital. Second, the representative family makes decisions regarding the optimal accumulation and utilization of the capital stock. The appendix also lists the linear approximations to each of the equilibrium conditions, where hatted variables represent logarithmic deviations from a deterministic steady state (identified by the absence of a time subscript). In total, there are 18 equations that determine the recursive equilibrium laws of motion for the following 18 variables: $\left\{\hat{\lambda}_{t}, \hat{N}_{t}, \hat{C}_{t}^{e}, \hat{C}_{t}^{u}, \hat{R}_{t}, \hat{\pi}_{t}, \hat{q}_{t}, \hat{I}_{t}, \hat{u}_{t}, \hat{K}_{t+1}, \hat{r}_{t}^{k}, \hat{m}_{t}, \hat{w}_{t}, \hat{Y}_{t}, \hat{\Delta}_{t}, \hat{P}_{t}^{*}, \hat{m} c_{t}, \hat{\Theta}_{t}\right\} .{ }^{18}$

\section{A.1 General Equilibrium Equations}

$$
\begin{gathered}
\lambda_{t}=N_{t} \frac{1}{C_{t}^{e}}+\left(1-N_{t}\right) \frac{1}{C_{t}^{u}} \\
\lambda_{t}=\beta R_{t} E_{t}\left(\frac{\lambda_{t+1}}{\pi_{t+1}}\right) \\
1=q_{t}\left[1-\Phi^{\prime}\left[\frac{I_{t}}{K_{t}}-\delta\left(u_{t}\right)\right]\right] \\
\lambda_{t} q_{t}=\beta E_{t} \lambda_{t+1} r_{t+1}^{k} u_{t+1}+\beta E_{t} \lambda_{t+1} q_{t+1}\left(1-\delta\left(u_{t+1}\right)\right) \\
-\beta E_{t} \lambda_{t+1} q_{t+1}\left[\Phi\left[\frac{I_{t+1}}{K_{t+1}}-\delta\left(u_{t+1}\right)\right]-\Phi^{\prime}\left[\frac{I_{t+1}}{K_{t+1}}-\delta\left(u_{t+1}\right)\right] \frac{I_{t+1}}{K_{t+1}}\right] \\
r_{t}^{k}=\delta^{\prime}\left(u_{t}\right) \\
\lambda_{t}=\beta E_{t}\left(\frac{\lambda_{t+1}}{\pi_{t+1}}\right)+\nu m_{t}^{-\chi} \\
K_{t+1}=\left(1-\delta\left(u_{t}\right)\right) K_{t}+I_{t}-\Phi\left[\frac{I_{t}}{K_{t}}-\delta\left(u_{t}\right)\right] K_{t} \\
C_{t}^{u}=\mu C_{t}^{e}
\end{gathered}
$$

\footnotetext{
${ }^{18}$ The variable $q_{t}$ is the lagrange multiplier on the law of motion for capital (44) in the family's optimization problem. I solve the complete set of difference equations using the technique developed by Klein (2000).
} 


$$
\begin{gathered}
h w_{t}=\frac{1}{1-s}\left(\frac{\tilde{C}-1}{\tilde{C}}\right) C_{t}^{e} \\
Y_{t}=N_{t} C_{t}^{e}+\left(1-N_{t}\right) C_{t}^{u}+I_{t} \\
Y_{t} \Delta_{t}=\left(u_{t} K_{t}\right)^{\alpha}\left(N_{t} e h\right)^{1-\alpha} \\
P_{t}^{*} E_{t-1} \sum_{j=0}^{3} \beta^{j} \lambda_{t+j} Y_{t+j}\left[\prod_{\tau=1}^{j} \pi_{t+\tau}\right]^{\frac{1-\eta}{\eta}}=(1+\eta) E_{t-1} \sum_{j=0}^{3} \beta^{j} \lambda_{t+j} Y_{t+j} m c_{t+j}\left[\prod_{\tau=1}^{j} \pi_{t+\tau}\right]^{\frac{1}{\eta}} \\
1=\frac{1}{4} \sum_{j=0}^{3}\left(P_{t-j}^{*} \prod_{\tau=0}^{j-1} \pi_{t-\tau}^{-1}\right)^{-\frac{1}{\eta}} \\
\Delta_{t}=\frac{1}{4} \sum_{j=0}^{3}\left(P_{t-j}^{*} \prod_{\tau=0}^{j-1} \pi_{t-\tau}^{-1}\right)^{-\frac{1+\eta}{\eta}} \\
r_{t}^{k}=\alpha m c_{t}\left(u_{t} K_{t}\right)^{\alpha-1}\left(N_{t} e h\right)^{1-\alpha} \\
h w_{t}=(1-\alpha) m c_{t}\left(u_{t} K_{t}\right)^{\alpha}\left(N_{t} e h\right)^{-\alpha} e h \\
\Theta_{t}=\frac{m_{t}}{m_{t-1}} \pi_{t} \\
\ln \Theta_{t}=(1-\rho) \ln \Theta+\rho \ln \Theta_{t-1}+\varepsilon_{t}
\end{gathered}
$$

\section{A.2 The Linearized System}

$$
\begin{gathered}
\hat{\lambda}_{t}=\frac{(1-\mu) N}{(1-\mu) N-1} \hat{N}_{t}-\hat{C}_{t}^{e} \\
\hat{\lambda}_{t}=E_{t} \hat{\lambda}_{t+1}+\hat{R}_{t}-E_{t} \hat{\pi}_{t+1} \\
\hat{q}_{t}=\phi \delta\left(\hat{I}_{t}-\hat{K}_{t}\right)-\phi\left(\beta^{-1}-1+\delta\right) \hat{u}_{t} \\
\hat{\lambda}_{t}+\hat{q}_{t}=E_{t} \hat{\lambda}_{t+1}+\beta(1-\delta) E_{t} \hat{q}_{t+1}+\beta \phi \delta^{2} E_{t}\left(\hat{I}_{t+1}-\hat{K}_{t+1}\right)+\beta r^{k} u E_{t} \hat{r}_{t+1}^{k}-\beta \phi \delta r^{k} u E_{t} \hat{u}_{t+1} \\
\hat{r}_{t}^{k}=\varphi \hat{u}_{t} \\
\hat{m}_{t}=-\frac{1}{\chi} \hat{\lambda}_{t}-\frac{1}{\chi(R-1)} \hat{R}_{t} \\
\hat{K}_{t+1}=(1-\delta) \hat{K}_{t}+\delta \hat{I}_{t}-\left(\beta^{-1}-1+\delta\right) \hat{u}_{t} \\
\hat{C}_{t}^{u}=\hat{C}_{t}^{e} \\
\hat{w}_{t}=\hat{C}_{t}^{e} \\
\hat{Y}_{t}=\frac{C^{u}}{Y} \hat{C}_{t}^{u}-\frac{N C^{u}}{Y}\left(\hat{N}_{t}+\hat{C}_{t}^{u}\right)+\frac{I}{Y} \hat{I}_{t}
\end{gathered}
$$




$$
\hat{Y}_{t}+\hat{\Delta}_{t}=\alpha\left(\hat{u}_{t}+\hat{K}_{t}\right)+(1-\alpha) \hat{N}_{t}
$$

$$
\begin{aligned}
& P^{*}\left[1+\beta \pi^{\frac{1-\eta}{\eta}}+\beta^{2} \pi^{2 \frac{1-\eta}{\eta}}+\beta^{3} \pi^{3 \frac{1-\eta}{\eta}}\right] \hat{P}_{t}^{*}= \\
& (1+\eta) m c E_{t-1}\left[\hat{m} c_{t}+\beta \pi^{\frac{1}{\eta}} \hat{m} c_{t+1}+\beta^{2} \pi^{\frac{2}{\eta}} \hat{m} c_{t+2}+\beta^{3} \pi^{\frac{3}{\eta}} \hat{m} c_{t+3}\right] \\
& +\left[(1+\eta) m c \frac{1}{\eta}\left[\beta \pi^{\frac{1}{\eta}}+\beta^{2} \pi^{\frac{2}{\eta}}+\beta^{3} \pi^{\frac{3}{\eta}}\right]-P^{*} \frac{1-\eta}{\eta}\left[\beta \pi^{\frac{1-\eta}{\eta}}+\beta^{2} \pi^{2 \frac{1-\eta}{\eta}}+\beta^{3} \pi^{3 \frac{1-\eta}{\eta}}\right]\right] E_{t-1} \hat{\pi}_{t+1} \\
& +\left[(1+\eta) m c \frac{1}{\eta}\left[\beta^{2} \pi^{\frac{2}{\eta}}+\beta^{3} \pi^{\frac{3}{\eta}}\right]-P^{*} \frac{1-\eta}{\eta}\left[\beta^{2} \pi^{2 \frac{1-\eta}{\eta}}+\beta^{3} \pi^{3 \frac{1-\eta}{\eta}}\right]\right] E_{t-1} \hat{\pi}_{t+2} \\
& +\left[(1+\eta) m c \frac{1}{\eta} \beta^{3} \pi^{\frac{3}{\eta}}-P^{*} \frac{1-\eta}{\eta} \beta^{3} \pi^{3 \frac{1-\eta}{\eta}}\right] E_{t-1} \hat{\pi}_{t+3} \\
& +\left[(1+\eta) m c-P^{*}\right] E_{t-1}\left(\hat{\lambda}_{t}+\hat{Y}_{t}\right)+\left[(1+\eta) m c \beta \pi^{\frac{1}{\eta}}-P^{*} \beta \pi^{\frac{1-\eta}{\eta}}\right] E_{t-1}\left(\hat{\lambda}_{t+1}+\hat{Y}_{t+1}\right) \\
& +\left[(1+\eta) m c \beta^{2} \pi^{\frac{2}{\eta}}-P^{*} \beta^{2} \pi^{2 \frac{1-\eta}{\eta}}\right] E_{t-1}\left(\hat{\lambda}_{t+2}+\hat{Y}_{t+2}\right) \\
& +\left[(1+\eta) m c \beta^{3} \pi^{\frac{3}{\eta}}-P^{*} \beta^{3} \pi^{3 \frac{1-\eta}{\eta}}\right] E_{t-1}\left(\hat{\lambda}_{t+3}+\hat{Y}_{t+3}\right) \\
& {\left[\hat{P}_{t}^{*}+\pi^{\frac{1}{\eta}} \hat{P}_{t-1}^{*}+\pi^{\frac{2}{\eta}} \hat{P}_{t-2}^{*}+\pi^{\frac{3}{\eta}} \hat{P}_{t-3}^{*}\right]=\left[\pi^{\frac{1}{\eta}}+\pi^{\frac{2}{\eta}}+\pi^{\frac{3}{\eta}}\right] \hat{\pi}_{t}+\left[\pi^{\frac{2}{\eta}}+\pi^{\frac{3}{\eta}}\right] \hat{\pi}_{t-1}+\pi^{\frac{3}{\eta}} \hat{\pi}_{t-2}} \\
& \Delta \hat{\Delta}_{t}=-\frac{1}{4} P^{*^{-\frac{1+\eta}{\eta}}}\left(\frac{1+\eta}{\eta}\right)\left[\hat{P}_{t}^{*}+\pi^{\frac{1+\eta}{\eta}} \hat{P}_{t-1}^{*}+\pi^{2 \frac{1+\eta}{\eta}} \hat{P}_{t-2}^{*}+\pi^{3 \frac{1+\eta}{\eta}} \hat{P}_{t-3}^{*}\right] \\
& +\frac{1}{4} P^{*^{-\frac{1+\eta}{\eta}}}\left(\frac{1+\eta}{\eta}\right)\left[\pi^{\frac{1+\eta}{\eta}}+\pi^{2 \frac{1+\eta}{\eta}}+\pi^{3 \frac{1+\eta}{\eta}}\right] \hat{\pi}_{t} \\
& +\frac{1}{4} P^{*^{-\frac{1+\eta}{\eta}}}\left(\frac{1+\eta}{\eta}\right)\left[\pi^{2 \frac{1+\eta}{\eta}}+\pi^{3 \frac{1+\eta}{\eta}}\right] \hat{\pi}_{t-1}+\frac{1}{4} P^{*^{-\frac{1+\eta}{\eta}}}\left(\frac{1+\eta}{\eta}\right) \pi^{3 \frac{1+\eta}{\eta}} \hat{\pi}_{t-2} \\
& \hat{r}_{t}^{k}=\hat{m} c_{t}+(\alpha-1)\left(\hat{u}_{t}+\hat{K}_{t}\right)+(1-\alpha) \hat{N}_{t} \\
& \hat{w}_{t}=\hat{m} c_{t}+\alpha\left(\hat{u}_{t}+\hat{K}_{t}\right)-\alpha \hat{N}_{t} \\
& \hat{\Theta}_{t}=\hat{m}_{t}-\hat{m}_{t-1}+\hat{\pi}_{t} \\
& \hat{\Theta}_{t}=\rho \hat{\Theta}_{t-1}+\varepsilon_{t}
\end{aligned}
$$




\section{References}

Alexopoulos, Michelle. "Unemployment and the Business Cycle." Journal of Monetary Economics, March 2004, 51(2), pp. 277-98.

- "Shirking in a Monetary Business Cycle Model." Canadian Journal of Economics, August 2006a, 39(3), pp. 689-718.

. "A Monetary Business Cycle Model with Unemployment." forthcoming in Journal of Economic Dynamics and Control, September 2006b.

Anderson, Torben M. "Persistency in Sticky Price Models." European Economic Review, May 1998, 42(3-5), pp. 593-603.

Basu, Susanto. "Intermediate Goods and Business Cycles: Implications for Productivity and Welfare." American Economic Review, June 1995, 85(3), pp. 512-31.

Basu, Susanto and Fernald, John G. "Returns to Scale in U.S. Production: Estimates and Implications." Journal of Political Economy, April 1997, 105(2), pp. 249-83.

Basu, Susanto and Kimball, Miles S. "Cyclical Productivity with Unobserved Input Variation." National Bureau of Economic Research (Cambridge, MA) Working Paper No. 5915, February 1997.

Bergin, Paul R. and Feenstra, Robert C. "Staggered Price Setting, Translog Preferences, and Endogenous Persistence." Journal of Monetary Economics, June 2000, 45(3), pp. 657-80.

Blanchard, Olivier J. "Price Asynchronization and Price Level Inertia." in R. Dornbusch and M. H. Simonsen, eds., Inflation, Debt, and Indexation. Cambridge, MA: MIT Press, 1983, pp. 3-24.

Calvo, Guillermo A. "Staggered Prices in a Utility-Maximizing Framework." Journal of Monetary Economics, September 1983, 12(3), pp. 383-98.

Chari, V. V.; Kehoe, Patrick J. and McGratten, Ellen R. "Sticky Price Models of the Business Cycle: Can the Contract Multiplier Solve the Persistence Problem?" Econometrica, September 2000, 68(5), pp. 1151-79.

Cho, Jank Ok and Cooley, Thomas F. "The Business Cycle with Nominal Contracts." Economic Theory, June 1995, 6(1), pp. 13-33.

Christiano, Lawrence J.; Eichenbaum, Martin and Evans, Charles L. "Monetary Policy Shocks: What Have We Learned and to What End?" in John B. Taylor and Michael Woodford, eds., Handbook of Macroeconomics, 1999, Volume 1, Part 1, pp. 65-148. 
- "Nominal Rigidities and the Dynamic Effects of a Shock to Monetary Policy." Journal of Political Economy, January 2005, 113(1), pp. 1-45.

Dixit, Avinash K. and Stiglitz, Joseph E. "Monopolistic Competition and Optimum Product Diversity." American Economic Review, June 1977, 67(3), pp. 297-308.

Dotsey, Michael and King, Robert G. "Pricing, Production, and Persistence." Journal of European Economic Association, September 2006, 4(5), pp. 893-928.

Goodfriend, Marvin and King, Robert G. "The New Neoclassical Synthesis and the Role of Monetary Policy." in Ben S. Bernanke and Julio J. Rotemberg, eds., NBER Macroeconomics Annual 1997. Cambridge, MA: MIT Press, 1997, pp. 231-83.

Greenwood, Jeremy; Hercowitz, Zvi and Huffman, Gregory W. "Investment, Capacity Utilization, and the Real Business Cycle." American Economic Review, June 1988, 78(3), pp. 402-17.

Gruber, Jonathon. "The Consumption Smoothing Benefits of Unemployment Insurance." American Economic Review, March 1997, 87(1), pp. 192-205.

Huang, Kevin X. D. and Liu, Zheng. "Production Chains and General Equilibrium Aggregate Dynamics." Journal of Monetary Economics, October 2001, 48(2), pp. 437-62.

- "Staggered Price-Setting, Staggered Wage-Setting, and Business Cycle Persistence." Journal of Monetary Economics, March 2002, 49(2), pp. 405-33.

Kiley, Michael T. "Staggered Price Setting and Real Rigidities." Finance and Economics Discussion Series No. 46, Federal Reserve Board of Governors, August 1997a.

King, Robert G. and Watson, Mark W. "Money, Prices, Interest Rates, and the Business Cycle." Review of Economics and Statistics, February 1996, 78(1), pp. 35-53.

Klein, Paul. "Using the Generalized Schur Form to Solve a Multivariate Linear Rational Expectations Model." Journal of Economic Dynamics and Control, September 2000, 24(10), pp. 1405-23.

Leeper, Eric M.; Sims, Christopher A. and Zha, Tao. "What Does Monetary Policy Do?" Brookings Papers on Economic Activity, 1996, Issue 2, pp. 1-63.

Nakajima, Tomoyuki. "Optimal Monetary Policy With Imperfect Unemployment Insurance." Mimeo: Institute of Economic Research, Kyoto University, November 2005.

. "Unemployment and Indeterminacy." Journal of Economic Theory, January 2006, 126(1), pp. 314-27. 
Neiss, Katharine S. and Pappa, Evi. "Persistence Without too Much Price Stickiness: the Role of Variable Factor Utilization." Review of Economic Dynamics, January 2005, 8(1), pp. 231-55.

Rabanal, Pau and Rubio-Ramírez, Juan F. "Comparing New Keynesian Models of the Business Cycle: A Bayesian Approach." Journal of Monetary Economics, September 2005, 52(6), pp. 1151-66.

Rotemberg, Julio J. "Prices, Output and Hours: An Empirical Analysis Based On a Sticky Price Model." Journal of Monetary Economics, June 1996, 37(3), pp. 505-33.

Shapiro, Carl and Stiglitz, Joseph E. "Equilibrium Unemployment as a Worker Discipline Device." American Economic Review, June 1984, 74(3), pp. 433-44.

Taylor, John B. "Aggregate Dynamics and Staggered Contracts." Journal of Political Economy, February 1980, 88(1), pp. 1-23.

Yun, Tack. "Nominal Price Rigidity, Money Supply Endogeneity, and Business Cycles." Journal of Monetary Economics, April 1996, 37(2), pp. 345-70. 